\title{
Framing the 'Scroungers': The Re-Emergence of the Stereotype of the Undeserving Poor and Its Reflection in the British Press
}

\begin{abstract}
The article deals with British press coverage of a social group traditionally referred to in conservative discourse as the undeserving poor. The perception of the poor as either deserving or not deserving of state assistance on a moral basis is put into the context of the present public financial crisis, in which a justification for welfare cuts is being sought. It is shown that conservative-minded British papers (The Times, The Telegraph and The Daily Mail) uphold the Coalition government's hardened attitude towards benefits claimants, while progressiveminded papers (The Guardian, The Independent) refute the existence of the undeserving poor, looking instead for structural explanations of poverty-related phenomena. The main frames used to depict the undeserving poor are identified as fecklessness, anti-social behaviour and a something-for-nothing culture. The article draws on the work of frame theorist Shanto Iyengar and linguist George Lakoff, as well as on various social research reports on poverty in Britain.
\end{abstract}

Key words

Framing; undeserving poor; welfare reform; claimants; David Cameron

\section{Introduction}

Ever since the establishment of the Tudor Poor Laws, governments in Britain have striven to contain and control poverty, a persistent feature of British society despite the country's growing wealth over the centuries. The measures taken in various periods have been informed by the prevailing understanding of poverty and its causes. One of the most resilient poverty-related concepts has been that of the deserving and undeserving poor, dominating the social debate in certain periods while giving way to more compassionate concepts at other times. The purpose of 
this paper is to demonstrate that in the wake of the economic crisis of 2008, the morally charged concept of the undeserving poor has been enjoying its renaissance, both among the political establishment and the newspaper commentariat. It is argued that the frames applied in the depiction of the poor in the British media, often copying the government rhetoric, represent a throwback to the Victorian era, in which poverty was understood as an individual failing worthy of denouncement rather than a structural problem caused by larger economic and social forces.

\section{Theoretical concepts}

To understand the nature of the debate on the deserving/undeserving poor in both politics and the media, reference needs to be made to the concept and process of framing. According to Shanto Iyengar, a leading researcher in frame theory, framing represents a manner in which an opinion on an issue can be changed by emphasizing or de-emphasizing some of its specific aspects (Iygenar 2005: 5). To provide an example relevant to our purpose, the social group classified by the British Office for National Statistics as Grade E (i.e. the lowest-income social segment) can, for instance, be referred to in various situations as the poor, welfare claimants, the most vulnerable citizens, the underclass or food bank clients, each time with a different effect on the reader/listener.

In the context of media coverage, Iyengar distinguishes two categories of framing: thematic and episodic. Thematic framing presents an issue impersonally, focusing on the bigger picture and providing information such as statistics or expert opinions. On the other hand, episodic framing covers issues as individual instances or specific events, with little coverage of the underlying context. While both approaches are used, episodic framing tends to be more prevalent in newspaper coverage owing to its more direct appeal on readers (Iyengar 2005: 6).

In relation to the framing of political agendas, two contrasting metaphor-based cognitive models, called the strict father model and the nurturant parent model, have been proposed by the linguist George Lakoff (2004: 6) to refer to the conservative and progressive world view, respectively. These two models are of considerable use for the analysis of the discourse on the poor, and will be referred to throughout the text.

According to Lakoff, the strict father model perceives the world as a dangerous place, maintaining that there is absolute good and evil in it. It is the role of the strict father as the moral authority to induce correct behaviour in the children through strong discipline. Behaving morally and acting in one's self-interest leads to prosperity and success in the competitive world. In contrast to the patriarchal strict father model, the gender-neutral nurturant parent model is based on nurturing the inherent goodness of the children through providing protection, empathy and guidance towards a fulfilled life (Lakoff 2004: 7-8).

It is evident from the above that the concept of the deserving and undeserving poor operates within the strict father model. Simultaneously, it can be argued that 
a policy based on the nurturant parent model would refrain from making such a distinction, considering the poor as deserving of protection whatever the causes of their poverty.

\section{Historical background}

The understanding of poverty and its root causes has undergone substantial evolution over the centuries. Before the advent of the Modern Age, the presence of the poor was accepted as an inevitable, even natural, condition of an organic, hierarchical, God-ordained society. As argued by social historian Michael M. Katz (2013): "For most of recorded history, poverty reflected God's will. The poor were always with us. They were not inherently immoral, dangerous, or different. They were not to be shunned, feared, or avoided."

With the advent of early modern society and the concomitant economic and social changes (most notably the transition from feudal to capitalist economy), the understanding of poverty underwent fundamental transformation: from a natural condition, it turned into a social problem (Himmelfarb 1984). With monasteries, traditional centres of care of the poor, dissolved by Henry VIII's administration, the role of the "problem solver" was assumed by the state, resulting in the reliefadministering legislation commonly known as the Poor Laws.

To determine eligibility for relief, the Poor Laws made a distinction between two kinds of poor. Roughly, the deserving poor included children, the sick, and the old, i.e. individuals unable to do work. Their treatment was a great deal more benign that that of the undeserving poor, comprising able-bodied unemployed of all kinds (referred to as rogues, vagrants, sturdy beggars, etc.). The undeserving poor were treated harshly, by a series of punitive or corrective policies reflecting their position as an anti-social segment in need of containment or elimination.

The $17^{\text {th }}$ and $18^{\text {th }}$ centuries saw the escalation of the rhetoric identifying the poor as immoral, as well as a burden on society and public finances. The widely held stereotypical view of how the undeserving poor conducted themselves has been summarized by historian Jeremy Seabrook in his book Pauperland, a history of poverty in Britain:

If these reasons for enduring poverty were insufficient, the most common of all was to treat the poor, those not exempt by an existential incapacity to provide for themselves, as though they were self-generating and existed for perverse moral reasons known only to themselves. This view makes them responsible for their own condition: inherent improvidence, prodigality and idleness. Accessory to their own misery, they breed irresponsibly, have no thought for the future, squander their substance in clement seasons and save nothing for hard times. They are addicted to luxury, drink and 'vice'. 
Throughout modern British history, this stereotype has shown remarkable resilience, re-emerging repeatedly under different political set-ups but with the basic structure unchanged, the "undeservingness" consisting in a mixture of laziness (both physical and mental), irresponsible childbearing, substance abuse and acquisitiveness, combined with the inability to defer gratification.

After a brief relaxation of attitudes towards the poor in the late $18^{\text {th }}$ century, the punitive approach to poverty returned in full force in the $19^{\text {th }}$ century in the form of new draconian poor law legislation. Under the Victorian canon of self-help and self-betterment, poverty was perceived as an individual moral failing and treated as such, with the workhouse, immortalized by Charles Dickens, being the chief means of administering poor relief.

Boosted by the groundbreaking social research by philanthropist Seebohm Rowntree and the founder of the Salvation Army Charles Booth as well as the growing labour movement, the $20^{\text {th }}$ century saw a dramatic shift in the attitude to the poor. With poverty finally being recognized as a structural rather than an individual problem, the judgmentalism of the previous era gave way to a more sympathetic approach, manifesting in the creation of Britain's welfare state and its concept of welfare provision from the cradle to the grave (Dorling 2010: 24).

With the post-war decades of almost full employment, the concept of the undeserving poor was temporarily laid to rest, as most able-bodied men were in work. However, the arrival of Thatcherism, with mass unemployment in its wake, the concept resurfaced as whole communities found themselves out of work as a result of de-industrialization. Thatcher herself had little sympathy for economic inactivity, regarding it as individual failure to conform to the conditions of the market, as evident from the following comment made in her memoir The Downing Street Years:

The Victorians had a way of talking which also summed up what we were now discovering - they distinguished between the "deserving" and "undeserving" poor. Both groups should be given help: but it must be help of very different kinds if public spending is not just going to reinforce the dependency culture. (Thatcher 1993: 590)

However, despite her neo-Victorian attitude and despite the subsequent "welfare to workfare" rhetoric of the New Labour era with Tony Blair at the helm, the cradle-to-grave welfare state remained in place, growing is size rather than the opposite. It was the economic crisis of 2008 - and the subsequent switch to Conservative administration - that gave rise to the biggest challenge to the concept of modern welfare provision, a process accompanied by the use of loaded language to refer to its recipients and their social and moral character. 


\section{The undeserving poor in current political discourse}

The recent re-opening of the debate on the deserving/ undeserving poor has been unfolding in the context of the austerity agenda of David Cameron's coalition government, aimed at reducing Britain's staggering budget deficit of over one trillion pounds (Anderson 2014). To effect the deficit reduction, the Government announced a large-scale welfare reform, masterminded by the former Conservative leader Iain Duncan Smith, involving extensive benefit cuts. To reconcile the public with the potentially explosive policy, Cameron and his team reached for the age-old dichotomy between the strivers and the shirkers, shifting the poverty debate away from the focus on real need to emphasis on moral eligibility for assistance. The striving segment of the economically vulnerable class, repeatedly referred to as hard-working families, alarm-clock Britain, those doing the right thing, etc., to emphasize their moral entitlement, received assurances of the Government's being on their side: "We're getting behind working families who work hard and want to do the right thing" (quoted in Meredith 2013).

In contrast, those behaving in a way judged as socially and economically irresponsible, also referred to as the hard-to-reach, problem families, those having no stake in society, etc., were identified as the main target of the cuts:

Those within it grow up with a series of expectations: you can have a home of your own, the state will support you whatever decisions you make, you will always be able to take out no matter what you put in. This has sent out some incredibly damaging signals. That it pays not to work. That you are owed something for nothing. It gave us millions of working-age people sitting at home on benefits even before the recession hit. It created a culture of entitlement. And it has led to huge resentment amongst those who pay into the system, because they feel that what they're having to work hard for, others are getting without having to put in the effort. (quoted in Wintour and Mulholland 2012)

The source of the quotation above is David Cameron's 2012 speech on welfare, delivered in the Bluewater shopping centre in Kent, in which the Cabinet's antiwelfare attitude is laid bare. Rather than exploring the root causes of extensive welfare reliance, talk of "dependency culture" and "benefits lifestyle" is employed. Appealing to the traditional British sense of fair play, the government presents itself as a deliverer of social justice, preventing those "unfairly" claiming from abusing the benevolent system. Thus, Cameron's rhetoric, and the welfare reform as a whole, can be seen to carry a strong signature of the strict father approach.

Interestingly, the strict father line on benefit claimants is not a domain of the Conservative Party only; it also has its adherents in the Opposition camp. Perhaps the best-known of these is the maverick MP Frank Field, a former minister in Blair's government and currently the poverty tsar advising David Cameron. Despite his Labour affiliation, he holds some undeniably neo-Victorian social views and is 
widely known as a vocal critic of Britain's welfare system. Like the architects of the Victorian welfare reforms, Field believes in the need to distinguish between the deserving and undeserving claimants and warns that the current system plays into the hands of those who abuse the system immorally. In a nod to Thomas Hobbes, he expresses pessimism about the motives of welfare dependants: "It therefore pays to lie about one's earnings or to be inactive. The worst side of human nature is encouraged, the best is penalised" (quoted in Heffer 2012).

The case for the existence of the undeserving poor is thus voiced across the political spectrum. In addition, recent opinion surveys reveal falling support for welfare provision amongst the general public, especially amongst the cohort referred to as Generation Y, whose members feel resentful at the alleged abuse of benefits by workshy claimants. This, however, is in contrast with the real situation; according to official estimates, benefits expenditure only stands at 0.7 per cent of total benefit expenditure of $£ 1.2$ billion (Duffy et al. 2013: 34). Rather than a vast army of scroungers, Britain appears to have a different problem: a growing number of low-wage workers whose earnings are not sufficient to meet the basic living expenses (especially due to the high housing and energy prices), the deficit having to be covered by the state in the form of in-work benefits. Thus, the phenomenon of the working poor is putting a greater strain on the public finances than the phenomenon of welfare fraud, a fact often underemphasized in the government's rhetoric, as it undermines the undeserving poor argument.

\section{The undeserving poor in newspaper coverage}

\subsection{Sources and methodology}

To elicit the coverage of the undeserving poor in the British press, five sources have been selected: The Times, The Guardian, The Telegraph, The Independent and The Daily Mail, all in their online versions. The choice of the newspapers reflected the need to have the widest possible spectrum of political opinion represented - from left-leaning (The Guardian) to right-leaning (The Telegraph). The Daily Mail was included as a representative of the tabloid press. For the purposes of analysis, a corpus of 100 articles published between the years 2009 2014 was obtained from the above-mentioned sources by means of a number of search phrases (welfare, benefit cuts, claimants, undeserving poor). The corpus was content-analyzed with the following purposes:

a) to ascertain whether thematic or episodic framing prevailed

b) to ascertain whether the strict father or the nurturant parent prevailed

c) to elicit the frames most commonly applied to the undeserving poor

Due to the fact that the subject matter is framed very differently in the right- and left-leaning papers, each will be dealt with separately. 


\subsection{Right-leaning papers: general characteristics}

The shared characteristic of the right-leaning sources is that they all adopt the strict father attitude, thus corroborating the Coalition's narrative. They all distinguish between the deserving and undeserving poor, the former group including low-paid workers, children, the elderly and the truly disabled, and the latter comprising able-bodied non-working individuals of various types (with the exception of stay-at-home married mothers of small children, who are framed as deserving). Of the two groups, the undeserving poor are given far more extensive coverage.

The manner in which the strict father approach is communicated by individual right-leaning papers differs substantially depending on whether a quality paper or a tabloid is involved. The two quality papers (The Times and The Telegraph) make predominant use of thematic framing, the main focus of their attention being the Coalition government's welfare reform, presented as a much needed and long overdue step to tackle the endemic culture of welfarism. The architect of the reform, Iain Duncan Smith, is portrayed as a bold warrior facing a deeply ungrateful task of slaying the monster of socially destructive behaviour stemming from welfare dependency:

The deserving, decent poor are easily dealt with; it is the undeserving that will be the big headache for the next government. Mr Cameron should put Mr Duncan Smith in his Cabinet not just to implement the findings of his own report, but to mastermind the assault on a culture of fecklessness that an over-generous state and our failure to deal with the drugs problem have made one of the most toxic and profligate features of our society. (Heffer 2009)

In line with their predominantly thematic coverage of the subject matter, the rightleaning quality papers provide very few authentic examples of the undeserving poor, focusing instead on the dependency culture as a whole. When individual stories do appear, they often involve a person acting like some kind of prodigal son to the strict father; someone who, having lived the life of an undeserving shirker, has finally converted to, or at least accepted the need for, Duncan Smith's disciplinary gospel. Such is the case, for instance, of Deirdre Kelly aka White Dee, a single mother on benefits and the controversial star of Channel 4's "poverty porn" programme Benefits Street. Despite being portrayed in the programme as a loud-mouthed chronic skiver, on the pages of The Daily Telegraph she is cast into the unexpected role of a welfare reform defendant:

She backs the Work and Pensions Secretary Iain Duncan Smith's latest idea for pre-paid cards to prevent claimants spending their money on 'fags and booze. 'I'm in agreement with IDS' she says. 'He completely hit the nail on the head. Pre-paid cards are a very, very good idea for vulnerable people like drug addicts and alcoholics - but there are people on benefits who are more than capable of budgeting'. (Ridge 2014) 
White Dee's appreciation of Duncan Smith's mission, as well as her compliments addressed to the members of the Conservative Party conference to which she was invited as an unlikely special guest, are portrayed as almost redemptive; she is the lost soul who has "seen sense". The tone of the coverage, however, remains patronizing and contains some obvious, albeit muted, instances of class stereotyping (allusions to her appearance, etc.).

In contrast to the quality papers, the right-leaning tabloid paper Daily Mail, faithful to its sensationalist policy, appears far less conciliatory and chooses to attack the undeserving poor head-on. In an overwhelmingly episodic coverage of benefit claimants, it employs the strategy of picking out extreme cases of their behaviour and portraying them as the norm. No sympathy for the claimants' circumstances is shown: they are presented as a threat to society and violators of nearly all principles of decent conduct. Even articles that, at face value, portray some form of suffering on the part of welfare recipients, contain criticism that completely overrides the sympathy. This can be seen in the story of Christina Briggs, covered in an article called It's Not Easy Being Overweight and on Benefits, Says 25 Stone Mother-of-Two Who Wants MORE Money from the Government to Help Her Diet (Waterlow 2014). The unusually long headline already contains a number of stereotypes: being obese, living off benefits, being unable to take control of one's life, demanding money from the government. As the article unfolds, more stereotypes emerge:

She insists she can't get a job to gain more money because she's needed at home to care for her children 'I tried swimming but it cost $£ 22$ a month and it meant I had to cut back on my favourite pizza and Chinese takeaways'. Unemployed Christina gets $£ 20,000$ in benefits a year and lives in a council house with her two children by different fathers, Helena, 10, and Robert, two. She left school as a teenager after falling pregnant with her daughter following a one night stand. The family feast everyday on takeaways, chocolate and crisps as Christina says they can't afford low fat foods. As a result, the mother is currently a dress size 26. (Waterlow 2014)

Thus, the additional examples of defective behaviour include sexual promiscuity, teenage pregnancy, inability to obtain proper education and failure to take proper care of oneself and one's family. Rather than presenting her case as unusual due to the high accumulation of personal issues, the paper casts her in the role of a typical member of the undeserving poor.

\subsection{Right-leaning papers: frames used to depict the undeserving poor}

The analysis of the corpus of right-leaning articles has revealed a number of frames in which the stereotype of the undeserving poor is communicated to the readership. These frames can be found in both the tempered coverage of the quality papers and the aggressive, sensationalist delivery of the Daily Mail. 
The names of the frames are the author's own and are described in more detail below.

\subsubsection{The fecklessness frame}

The frame most visibly applied to the undeserving poor can be referred to as fecklessness. This adjective, popular with not only newspapers but also conservativeminded politicians, refers to the general inability to make responsible choices in life, thus generating the need for the strict father to step in and intervene. Fecklessness has many manifestations but none seems to cause so much moral outrage of the newspaper commentariat as the unhealthy lifestyle of the undeserving poor. Consistently blamed for ignoring the basic principles of healthy diet and proper care of the body, they are portrayed as a nation of junk-food gorging, obese TV addicts with a plethora of unhealthy habits such as binge drinking and drug abuse (see also Tihelková 2013: 138). Their self-destructive lifestyle is all the more culpable as it generates extra costs to the National Health Service. This damning view of the "irresponsible" lifestyle of the poor, contrasted with the "virtuous" lifestyle of the middle classes, takes no consideration of the wider social situation of the poor, ignoring the correlation between economic deprivation and substance abuse. Instead, a preachy attitude is employed:

It isn't fat and sugar that kills people so much as fecklessness: a trait that will always be concentrated in the less well-off. Of course there are poor people who eat sensibly and there are wealthy people who smoke, drink and snort their way to oblivion, but the reason that more than twice as many people die before the age of 75 in Manchester, England's unhealthiest district, than do in Wokingham, the healthiest, is because on the whole people in middleclass commuter towns look after themselves better, The same values that help them to postpone reward to train for jobs and to pay their mortgages help them to refrain from excess at the dining table. (Clark 2013)

Another major way in which fecklessness manifests itself is the inability to establish and maintain functional relationships, leading to promiscuity, broken family life, teenage pregnancy and child neglect; all this, obviously, at a staggering expense to the welfare state expected to foot the bill. Single mothers on benefits, in particular, are targeted as the embodiment of feckless lifestyle, often to the point of caricature not dissimilar to Matt Lucas' portrayal of Vicky Pollard, the dimwit chavette from the controversial TV series Little Britain (Jones 2012: 128). The dysfunctional lives of the undeserving poor are framed as antithetical to the nation's (i.e. middle-class) values of respectability and social responsibility; indeed, as a direct threat to the nation's moral health. No consideration is given to some wider trends that may have contributed to the break-up of once functioning and closely-knit working class communities, as documented, for instance, by social commentator Owen Jones in his book Chavs: Demonization of the Working 
Class, where an account is provided of the destructive effect of the 1980s deindustrialization on the social fabric:

When I asked Mrs Parry what impact the pit's closure had on the community, she interrupted me before I had even finished the question. 'We died!' she responded with a combination of grief and conviction. 'Once all the mines closed, all the community had gone. It's just been a big depression ever since, just struggling to survive, that's all. Both her father and her thenhusband were miners. They split up the year he lost his job. 'We owed not just our livelihoods, but our lives to the pits as well. My dad retired, and then he died. My marriage broke up.' (Jones 2012; 185)

In contrast to Jones' acknowledgment of the complexity of the issue, the rightleaning newspapers assign the blame for the "broken" lives to the poor alone, with their fecklessness being presented as the primary cause. As a solution, strict father measures (such as benefit cuts, fiscal policies to favour the traditional family, etc.) are proposed.

\subsubsection{The anti-social behaviour frame}

The second frame applied to the undeserving poor could be broadly formulated as anti-social behaviour. It can be understood as a logical outcome of fecklessness, as unhealthy lifestyles and dysfunctional family patterns are believed to give rise to unhealthy and dysfunctional social conduct. As perpetrators of public disorder, the undeserving poor are presented as a wilful force violating the peace and quiet of the law-abiding majority. No consideration, again, is given to the possible deeper causes of such behaviour (social deprivation, lack of job opportunities, life on ghettoized housing estates with few positive social or cultural outlets); where some explanation going beyond individual conduct is provided after all, welfarism is usually identified as the principal culprit.

Families of welfare dependants are stereotypically portrayed as a public nuisance, as neighbours from hell terrorizing their environment with their blazing rows, loud music and dangerous dogs (usually pitbulls or Rottweilers, stereotypically belonging to "boyfriends" of single mothers). Younger members of the undeserving poor are referred to as thugs, chavs or ladettes (noisy, hard drinking women), taxpayer-funded to inflict misery on the community in the form of loutish behaviour, drug-related offences, vandalism or street violence. There is a generational aspect to this; the youngsters are shown as victimizing the elderly; the forces of chaos are taking on the pillars of order and civility. Because the fabric of society has been undermined and dysfunctional lifestyles have taken over, there is little chance that the youths would mature and assume a more ordered lifestyle like their predecessors, the Teddy Boys, Mods or Rockers eventually did. A culture of perpetual delinquency appears inevitable: 
That was then. This is now. The sort of kids who are hanging round these streets, to the alarm and consternation of their neighbours, are not only unlikely to "settle down" into marriage and family commitment: they will quite possibly never grow up in the old-fashioned sense at all. If they father children, they will make no permanent alliance with the mothers of those children. If they do not find steady employment, they will not have to be concerned about punctuality, reliability or the effect that getting into trouble with the police might have on their employers. There is good reason why the fourteen year old yob of today causes so much fear and anger in his neighbourhood: because most of his community is aware that this behaviour - and his expectations - are unlikely to change much between now and his thirtieth birthday. And the prospect of a pack of twenty-five year olds shouting on your doorstep is not something anybody would dismiss. (Daley 2013)

Again, little consideration is given to the different economic reality of today's generation of young people, especially the lack of steady jobs paying a living wage to which the angry young men of the past could look forward, along with the corresponding social status. The strict father rhetoric sees irresponsible children refusing to grow up, not individuals trapped in a society offering few prospects of economic independence and social mobility.

\subsubsection{The something-for-nothing culture frame}

The last major frame identifiable in the right-leaning coverage may be referred to as something for nothing culture, i.e. pervasive economic and social passiveness, reliance on state assistance and a dire lack of aspiration to advance in life through paid work.

The working classes of the past, admittedly, also tended to be portrayed as unambitious, preoccupied with bread-and-butter issues and preferring instant gratification to planning for a better future, a stereotype to which the 1980s Sierra Man (a skilled working-class individual aspiring to become middle class in Thatcher's Britain) was something of an exception (Biressi and Nunn 2013: 30). However, the social immobility of the working classes was not perceived as a problem because of their involvement in productive work. While unambitious, they were "deserving".

In contrast, the economic inactivity of today's able-bodied welfare claimants provokes indignation among the right-leaning commentariat, with their unemployment being seen not as a result of unfavourable labour market conditions but of the unwillingness to pursue employment opportunities, to "get on their bike", as iconically expressed by the 1980 s politician Norman Tebbbit. Their reliance on welfare is seen as a personal choice; not a result of economic adversity. Accordingly, language reflecting this view is used in the coverage, referring to individuals as "shirkers", "lazy scroungers" or "freeloaders" who are "sponging off the state", "milking the system", etc. Young people not holding a job are 
frequently cast into the NEET category (not in Education, Employment or Training) and portrayed as socially disruptive as well as very costly to the state (the costs including benefits, lost tax, the costs of providing extra health services and costs related to their criminal activity).

On occasions, the passivity and dearth of aspiration of those reliant of welfare is denounced indirectly, for instance through extolling the virtues of another group perceived as active and productive. Such is the case of an article penned by Simon Heffer, a well-known conservative-minded commentator and defender of traditional values, with the lengthy title The Victorians Were Dynamic, Hugely Inventive and Deeply Caring, Says the Mail's SIMON HEFFER in His MuchAcclaimed New Book (Heffer 2013). While the purpose of the article is to promote Heffer's book on Victorian society, it simultaneously serves as an attack on today's undeserving poor, presented as antithetical (non-dynamic, uninventive and uncaring) to the Victorians. The article also praises free trade and state nonintervention, claiming that the greatest deal of social improvement in the Victorian era was achieved by the voluntary sector enabled by the state to do its work; a view in line with David Cameron's idea of Big Society. The article frames the issue thematically, with state welfarism being held responsible for the decline of aspiration and entrepreneurial spirit.

In addition to general welfare dependence, the right-leaning press devotes a great deal of coverage to welfare fraud. Differing from anti-social behaviour in that it does not involve a physical disruption of public order, cheating the welfare system nevertheless appears to be causing as much resentment, as it constitutes a violation of the principle of fairness as well as an unpardonable drain on the resources created by hard-working law-abiding and tax-paying "coping class". Interestingly, this frame seems to run counter to the fecklessness frame. In the former, the undeserving poor are portrayed as incapable and self-destructive. Here, however, they are often shown as cunning manipulators, knowing their way around the system. A typical example of such behaviour is the stereotype of the "welfare queen" (Gilman 2014: 247). Although originally coined in the United States, this stereotype also appears to be firmly established in British social discourse, referring to a (usually) single mother with multiple children who makes a comfortable living fraudulently collecting excessive welfare benefits. Unlike her American counterpart, however, the stereotypical British welfare queen is a representative of the white underclass, not a member of an ethnic minority; indeed, compared to poverty coverage in the USA, ethnicity plays a somewhat less prominent role in reporting on the British undeserving poor in general (see Larsen 2014).

The Daily Mail, in particular, appears to be preoccupied with women cast into the welfare queen category. Seen through the strict father lens of the paper, these women are portrayed as an embodiment of "undeservingness", as seen in example of the overweight single mother Christina Briggs discussed above, combining dysfunctional personal behaviour with socially parasitic behaviour. To convey the paper's moral indignation, extreme and heavily stereotyped cases are often 
selected for coverage; this is usually already apparent from the headline, e.g. Grandmother, 61, Who Has Brought Up Seven Children on Benefits Now Wants Another Baby With Her Toy Boy Lover, 34, After Op in NHS Boosted Her Sex Life (Bloom 2015). Less frequently, similar coverage is given to welfare-dependent men who have fathered a larger-than-average number of children, such as Peter Rolfe, an "unemployed father of 26" (Greenhill 2015). The stories of these individuals are framed in such a way as to arouse resentment at the burden they represent to the productive society.

Another of the Daily Mail's tabloid-style strategies is to select stories in which benefit claimants are ridiculed in some way. Making them an object of mockery makes it possible to question their eligibility for state relief. A case in point is an article titled Benefit Cheat? Yes, But I Was Having an Out of Body Experience at the Time ... The Absurd and Ridiculous Excuses Spouted by the Public Handout Fraudsters (Cohen 2014), using a number of bizarre claims to disqualify the legitimacy of welfare claims in general.

The abuse of the welfare system is shown at times to go hand in hand with the perceived greed of the undeserving poor. In contrast to the hard-working, gratification-deferring middle class, the undeserving poor are depicted as craving consumer goods and entertainment at the expense of the piggy bank of the state:

Headline after headline shows the extent people will go to to take advantage of the goodwill of the Government and waste money on booze, fags and designer clobber as they enjoy the life of Riley on behalf of the hardworking taxpayer. And let's not forget the fit-as-a-fiddle claimants who run marathons and scuba dive to the deepest depths yet insist they can't walk to the end of their garden path. (Preece 2012)

The ultimate example of the perceived greed of the undeserving poor is presented in the coverage of food banks. Mushrooming all across Britain since the introduction of Iain Duncan Smith's welfare reform, food banks often represent the last resort for individuals and families affected by the benefit cuts. Some politicians, such as the Conservative Minister Michael Gove, controversially ascribed their expansion to the inability of poor people to budget properly. However, the right-leaning press goes even further, presenting the undeserving poor as actively abusing the food bank services, as reported in the article titled Unpalatable Truth About Food Banks the Left Finds so Hard to Swallow: Political Football and Undeserving Claimants Distract from the Many Who Are in Genuine Need, which quotes examples of claimants seeking help from food banks after having squandered their benefits on drinks and drugs or including on other forms of fecklessness:

Come Monday, they have no money left. Then they just ask the Sure Start nursery staff where they take their kids for vouchers. They just fill out a form and lie. It's very easy and very cheeky.' Miss Sanders says that such people felt no shame in taking food donated by kind-hearted volunteers: 'Their 
attitude is to hell with them. It doesn't worry them. Benefits cash isn't for people to go out and get drunk on. But they seem to think that they're entitled to it. (Bird 2014)

Again, presenting one or two exceptional cases as the norm, the whole issue is reframed: food bank users are not victims of harsh welfare cuts by an uncaring government but social parasites abusing the well-intentioned society's generosity.

\subsection{Left-leaning papers: challenging the concept of the undeserving poor}

Not entirely unexpectedly, the left-leaning press frames the phenomenon of the undeserving poor in a radically different manner from the right-leaning press. Here, the very concept of "undeservingness" is rejected altogether; the poor are not divided into categories based on moral judgement. Greater consideration is given to underlying structural causes of welfare dependency and related phenomena, with Cameron's government subjected to criticism for allegedly failing to grasp the fact that the origins of poverty are more likely to be found in wider social inequalities than in the unwillingness to work:

Amid the Conservatives' self-ordained mission to rid the country of poor people, it's striking how seldom they bother to consider where social inequality and poverty originate. For them, there is no genealogy to poverty, no roots in adolescence or childhood. Rather, for the Tory mind, poverty is something which working class people simply choose on their eighteenth birthday. One of the most striking and paradoxical flaws of Conservative ideology is that they denounce poverty and state dependency on the one hand, and create it on the other. They deprive children of opportunities and resources, then decry the same people for failing to 'make it in the world' once they become adults. (Fenton 2015)

While some left-leaning columnists perceive the undeserving poor discourse as an example of the government's lack of understanding of the mechanisms of poverty, others go further, claiming that it clearly serves a utilitarian purpose of justifying the extensive welfare cuts; a Guardian editorial, for instance, argues that:

"Now as in the past, the undeserving poor make an easy and popular target, especially when public money is tight again. Which is why references to fecklessness and irresponsibility have become such effective drivers of the coalition's welfare reform legislation. (Rich and Poor 2012)

Contrary to the strict father approach of the right-leaning press, the left-leaning press largely addresses the issue from the position of the nurturant parent, empathizing with the poor regardless of their circumstances. Thus, the blame assignment is reversed: instead of a prudent government dealing with feckless paupers, 
there is an elite group of Old Etonian toffs inflicting insensitive policies on the society's most vulnerable. Accordingly, Iain Duncan Smith, the hero of the rightwing discourse, emerges as the Guardian columnists' ultimate wrongdoer.

Consistent with the nurturant parent's approach, assumptions of inherent social defectiveness are absent from the left-leaning discourse. The problematic behaviour of some welfare claimants is explained as a logical outcome of a deeply unfair economic and social system where human dignity is difficult to maintain. Thus, the prevailing frame for the poor is that of the victims of economic and social injustice.

Within this frame, the idea of the workshy poor is called into question. Life on benefits is not presented as a lifestyle of choice but of necessity due to the unavailability of proper jobs paying a living wage. On the highly deregulated and globalized labour market, the jobs on offer are mostly short-term, insecure, low-paid ones, offering little more than the minimum wage and often failing to guarantee a sufficient number of hours worked (cf. Tihelková 2014: 50). Thus, people forced off the benefits into paid work find themselves in much deteriorated and highly precarious circumstances. Especially for breadwinners, reluctance to accept such jobs is shown as understandable, and the government's insistence on the so-called work ethic framed as hypocritical. As argued by Guardian columnist Suzanne Moore:

Indeed, phrases such as "hardworking families" make me gag. The work ethic, the faith before which we are to prostrate ourselves, has a context. That context is that we are all supposed to compete not just with each other but with huge, unregulated global workforces such as China's. The work ethics becomes part of a race to the bottom of wage slavery. [..] In a world of parttime work and zero-hour contracts, workers' rights are virtually nonexistent. Yet this is what those at the very bottom of the pile must aspire to, as they sit preparing CVs for nonexistent jobs to send to companies that are suspicious of people who have been forced to do menial tasks. (Moore 2014)

In an attempt to communicate the nurturant parent's view, the left-leaning papers use a strategy opposite to that of the right-leaning papers. Rather than focusing on the most extreme examples of misbehaviour and benefit abuse, they deliver poignant stories of hardship experienced by those affected by the harsh economic and political climate: mothers struggling to feed and clothe their children (a rebuke to the Daily Mail's welfare queens), victims (often disabled) of the bedroom tax, individuals driven to suicide as a result of benefit cuts or disease-stricken claimants declared fit for work by the new policies. The use of episodic framing helps to generate sympathy for those affected by the draconian welfare policies, a case in point being the story of Sheila Holt, an incapacitated claimant reported by The Independent as having "received a letter from the Department of Work and Pensions demanding that she enter the second stage of her 'intensive jobfocused activity'. Unfortunately, she couldn't comply as she was in a coma, and had been for several weeks" (Jivanda 2014). 
In making a case for the victimhood of the claimants, parallels are drawn between the current austerity-driven politics and the harsh Elizabethan or Victorian poor laws with their punitive and dehumanizing approaches to the poor. Echoes of the old Poor Law system are identified both in the "workfare" programmes of unpaid labour devised by the Ministry of Work and Pensions (Seabrook 2012), as well as in the newly introduced policy of benefit sanctions (instant withdrawal of benefit payments), imposed by Jobcentre Plus offices on claimants who fail to comply with the stringent jobseeking procedures. Promoted by the government as incentives to improve work ethic and individual responsibility, the benefit sanctions are presented here as the ultimate example of the government's intent to punish the poor:

People are literally starving and their crime is that they dare to be poor and unemployed. [...] A jobseeker system that has sanctions at its centre is founded on the lie that the unemployed are too lazy to look for work unless they are threatened. The DWP acts as if it is training disobedient dogs. Stopping the money people need in order to eat is not the purpose of government. The benefit sanctions regime should be scrapped - but let's not stop there. The culture that created them needs shredding to pieces. (Ryan 2015)

Thus, those subject to benefit sanctions are framed not as feckless individuals with insufficient motivation to find work, but as people facing massive challenges from a system that first makes them poor and then punishes them for their poverty; people whose agency is considerably limited under the present economic and social circumstances.

\section{Conclusion}

The analysis of the newspaper sources has revealed that, in line with the poverty discourse of Cameron's government, the right-leaning papers have been using the deserving/undeserving dichotomy as a basis of their coverage, with heavy stereotyping being applied to the group of able-bodied welfare claimants, viewed through the strict father lens as economically passive, unambitious and showing defective values and behaviour. No consideration appears to be given to the fact that the majority of today's welfare claimants are in paid work; similarly, the growing precarity of both employment and general living conditions seems to be ignored. Of all the right-leaning papers, The Daily Mail shows the least sympathy towards welfare recipients and, using episodic framing with extreme cases of benefit abuse or problematic behaviour, makes the strongest case for their undeservingness.

Left-leaning papers, on the contrary, have resisted applying the dichotomy, instead depicting welfare claimants through the nurturant parent angle as victims of an unfair economic system. Paying far greater attention to the underlying structural causes of poverty and welfare dependency, they generally hold the view that entitlement to welfare assistance arises on the basis of need, not on the basis of 
desirable personal conduct; the very fact of being poor makes one deserving of help. Furthermore, they are sceptical of the effectiveness of a system seeking to induce behavioural change in claimants through various punitive measures (e.g. withdrawal of benefits). The welfare agenda of Cameron's government is generally perceived as a form of culture war on the poor, taking Britain backwards to more Dickensian times. Out of the two papers analysed, The Guardian is more vocal in expressing these views, assuming almost an activist role in upholding the cause of a group of individuals seen, through the nurturing parent perspective, as unjustly stigmatized. In both instances, episodic framing is used to either uphold or refute the undeserving poor argument.

The findings in themselves are hardly surprising; the contrasting approaches were to be more or less expected. What is surprising, however, is the intensity with which they are expressed, whether in the form of Victorian-like moral indignation of The Daily Mail, manifesting at times in the denigration and caricature of benefit claimants, or in the form of the social justice activism on behalf of poor by The Guardian.

Halfway through the second decade of the twenty-first century, the issue of poverty and the understanding of its causes continue to divide public opinion, with conservative and liberal views of it clashing with increasing force as the social divide in Britain grows wider.

\section{References}

Anderson, Richard (2014) "UK Budget Deficit - All You Need to Know". BBC News, 21 February 2014. <http://www.bbc.com/news/business-25944653> Accessed on 25 February 2015.

Bird, Steve (2014) "Unpalatable Truth about Food Banks the Left Finds So Hard to Swallow: Political Football and Undeserving Claimants Distract from the Many Who Are in Genuine Need". The Daily Mail, 12 March 2014. <http://www.dailymail.co.uk/news/article-2579715/Unpalatable-truth-food-banks-Left-finds-hard-swallow-Political-football-undeserving-claimants-shame-genuine-need.html $>$ Accessed on 20 April 2015.

Biressi, Anita and Heather Nunn (2013) Class and Contemporary British Culture. Basingstoke: Macmillan.

Bloom, Dan (2015) "Grandmother, 61, Who Has Brought Up Seven Children on Benefits Now Wants Another Baby with Her Toy Boy Lover, 34, after Op on NHS Boosted Her Sex life." The Daily Mail, 21 January 2015. <http://www.dailymail.co.uk/news/article-2919685/Grandmother61-brought-seven-children-benefits-wants-baby-toy-boy-lover-34-having-op-NHS-boost-sexlife.html > Accessed on 20 April 2015.

Clark, Ross (2013) "Fecklessness, Not Sugar or Fat, Makes the Poor Unhealthy". The Times, 20 June 2013. <http://www.thetimes.co.uk/tto/opinion/thunderer/article3795487.ece> Accessed on 2 February 2015.

Cohen, Tamara (2014) "Benefit Cheat? Yes, But I Was Having an Out of Body Experience at the Time ... The Absurd and Ridiculous Excuses Spouted by the Public Handout Fraudsters". The Daily Mail, 29 August 2014. <http://www.dailymail.co.uk/news/article-2738102/Benefit-cheatYes-I-having-body-experience-time-The-absurd-ridiculous-excuses-spouted-public-handoutfraudsters.html> Accessed on 1 April 2015.

Dorling, Danny (2010) "Persistent North-South Divides." In: Neil Coe and Andrew Jones (eds.) The Economic Geography of the UK. London: Sage, 12-28. 
Daley, Jane (2013) "There Was a Time When Yobs Would Have Grown Up". The Telegraph, 12 November 2013. <http://blogs.telegraph.co.uk/news/janetdaley/100245567/there-was-a-timewhen-yobs-would-have-grown-up/> Accessed on 1 April 2015.

Duffy, Bobby, Suzanne Hall, Duncan O'Leary and Sarah Pope (2013) Generation Strains. A Demos and Ipsos MORI Report on Changing Attitudes to Welfare. London: Demos.

Fenton, Siobhan (2015) "If the Government Loathes Benefits Claimants So Much, Perhaps It Should Stop Creating Them". The Independent, 18 December 2015. <http://www.independent. co.uk/voices/if-the-government-loathes-benefits-claimants-so-much-perhaps-it-should-stop-creating-them-a6778661.html> Accessed on 20 May 2015.

Gilman, Michele Estrin (2014) "The Return of the Welfare Queen." Journal of Gender, Social Policy \& the Law. 22(2), 247-279. <http://digitalcommons.wcl.american.edu/cgi/viewcontent. cgi? article $=1632 \&$ context $=$ jgspl $>$ Accessed on 30 March 2015 .

Greenhill, Sam (2015) “The Amazing Family Tree Which Shows the Truly Chaotic Life of Britain's Most Feckless Father: 26 Children, 15 Women, £46k in Benefits, a Taxpayer-Funded Five-Bedroom Home and No Job". The Daily Mail, 29 January 2015. <http://www.dailymail.co.uk/news/ article-2931021/Britain-s-feckless-father-Unemployed-dad-26-children-15-women-receives46-000-handouts-just-given-five-bedroom-council-home.html> Accessed on 25 April 2015.

Heffer, Simon (2009) "The Undeserving Poor Will be David Cameron's Biggest Headaches". The Telegraph, 16 September 2009. < http://www.telegraph.co.uk/comment/columnists/simonheffer/6194873/The-undeserving-poor-will-be-David-Camerons-biggest-headache.html > Accessed on 6 April 2015.

Heffer, Simon (2012) "Undeserving State-Funded Minority Will No Longer Enjoy the Same Lifestyle as Hardworking People". The Daily Mail, 26 October 2012. <http://www.dailymail.co.uk/ debate/article-2223822/Undeserving-state-funded-minority-longer-enjoy-lifestyle-hardworkingpeople.html > Accessed on 5 December 2014.

Heffer, Simon (2013) “The Victorians Were Dynamic, Hugely Inventive and Deeply Caring, Says the Mail's SIMON HEFFER in His Much-Acclaimed New Book". The Daily Mail, 10 October 2013. <http://www.dailymail.co.uk/debate/article-2453136/The-Victorians-And-The-Birth-OfModern-Britain-SIMON-HEFFERs-new-book.html> Accessed on 10 December, 2014.

Himmelfarb, Gertude (1984) "The Idea of Poverty". History Today, 34 (4), 4 April 1984. <http:// www.historytoday.com/gertrude-himmelfarb/idea-poverty> Accessed on 13 December 2014.

Iyengard, Shanto (1995) "Speaking of Values: The Framing of American Politics". The Forum. 3 (3), Article 7. <http://pcl.stanford.edu/common/docs/research/iyengar/2005/speaking.pdf> Accessed on 13 December 2014.

Jivanda, Tomas (2014) "Woman in Coma Told to Find Work by DWP: Minister Apologises." The Independent, 28 February 2014. <http://www.independent.co.uk/news/uk/home-news/woman-in-comatold-to-find-work-by-dwp-minister-apologises-9159394.html $>$ Accessed on 20 December 20, 2014.

Jones, Owen (2012) Chavs. The Demonization of the Working Class. London: Verso.

Katz, Michael (2013) "The Biological Inferiority of the Undeserving Poor". Social Work and Society. International Online Journal. 11 (1). <http://www.socwork.net/sws/article/view/359/709> Accessed on 13 December, 2014.

Larsen, Christian Albrekt (2014) "The Poor of the Mass Media: Negative Images in the US and UK versus Positive in Sweden and Denmark". Poverty, 148, 14-17. Available from http://www.cpag. org.uk/sites/default/files/CPAG-the-poor-of-the-mass-media-Jul14.pdf.

Meredith Charlotte (2013) "David Cameron: 'We Need to Help Hard-Working Families With Their Household Bills"”. The Daily Express, 26 April 2013. <http://www.express.co.uk/news/ uk/394950/David-Cameron-We-need-to-help-hard-working-families-with-their-householdbills $>$ Accessed on 13 December 2014.

Moore, Suzanne (2014) "Let's Call Help to Work What It Really Is: Punishment of the Undeserving Poor". The Guardian, 30 April 2014. <http:/www.theguardian.com/commentisfree/2014/apr/30/ help-to-work-is-really-punishment-unemployed-people > Accessed on 13 December 2014. 
Preece, Francesca (2012) "British Bill of Rights? Sounds More Like Us Footing the Bill for the 'Rights' of the Undeserving”. The Daily Mail, 12 July 2012. <http://www.dailymail.co.uk/debate/article-2172442/British-Bill-Rights-More-like-heres-rights.html > Accessed on 20 March 2015.

"Rich and Poor: Deserving and Undeserving". The Guardian, 271 1012. <http://www.theguardian.com/commentisfree/2012/jan/27/rich-poor-deserving-undeserving > Accessed on 20 March 2015.

Ridge, Sophy (2014) "White Dee Interview: 'What I Really Thought of Conservative Party Conference and All Those Tories"”. The Telegraph, 1 October 2010. $<\mathrm{http}: / / w w w . t e l e g r a p h . c o . u k /$ women/womens-life/11131506/White-Dee-interview-what-I-really-thought-of-ConservativeParty-conference-and-all-those-Tories.html?mobile=basic $>$ Accessed on 20 March 2015.

Ryan, Frances (2015) "The Benefit Sanctions System Should be Scrapped". The Guardian, 25 March 2015. <http://www.theguardian.com/commentisfree/2015/mar/25/benefit-sanctions-regime-should-be-scrapped-independent-review > Accessed on 26 May 2015.

Seabrook, Jeremy (2012) “Cameron's Attack on the 'Feckless Poor' Has a Very Long History”. The Guardian, 26 June 2012. <http://www.theguardian.com/commentisfree/2012/jun/26/fecklesspoor-cameron-long-history> Accessed on 23 March 2015.

Seabrook, Jeremy (2013) Pauperland. A Short History of Poverty in Britain. London: C. Hurst\& Co. Kindle edition.

Thatcher, Margaret (1993) The Downing Street Years. London: Harper Collins.

Tihelková Alice (2013) "Portrayal of the North-South Divide in the British Press" In American and British Studies Annual, Volume 6. Pardubice: Univerzita Pardubice, 134-144.

Tihelková, Alice (2014), "The Social Identity of the Precariat, Britain's Emerging Class." Hradec Králové Journal of Anglophone Studies, Vol. 1, No. 2. Hradec Králové: Department of English Language and Literature, University of Hradec Králové, 48-55.

Waterlow, Lucy (2014) "It's Not Easy Being Overweight and on Benefits, Says 25 Stone Motherof-two Who Wants MORE Money from the Government to Help Her Diet." The Daily Mail, 24 September 2014. $<$ http://www.dailymail.co.uk/femail/article-2768442/It-s-not-easy-overweightbenefits-says-25-stone-mother-two-wants-MORE-money-government-help-diet.html $>$ Accessed on 15 January 2015.

Wintour, Patrick and Hélène Mulholland (2012) "Cameron Announces Tory Plan to Slash Benefits". The Guardian, 26 June 2012. <http://www.theguardian.com/politics/2012/jun/25/camerontories-slash-benefits> Accessed on 13 December 2014.

Alice Tinelková studied History as well as English and American Studies at Charles University in Prague, where she also obtained her PhD in English Language in 2006. In 2002, she joined the Department of the English Language and Literature, Faculty of Arts, University of West Bohemia in Pilsen, where she has been teaching and researching British Cultural Studies. Her main focus is the structure and character of contemporary British society. She is dedicated to developing innovative and student-friendly ways of teaching British Cultural Studies, with emphasis on the latest developments on Britain's social scene.

Address: Alice Tihelková, Katedra anglického jazyka a literatury FF ZČU, Sedláčkova 15, Plzeň 306 14, Czech Republic. [email: atihelko@kaj.zcu.cz] 
